\title{
Article
}

\section{The role of line managers in creating and maintaining healthy work environments on project construction sites}

Townsend, Keith, Loudoun, Rebecca and Markwell, Katherine Available at http://clok.uclan.ac.uk/33465/

Townsend, Keith, Loudoun, Rebecca and Markwell, Katherine ORCID: 00000001-6349-3525 (2016) The role of line managers in creating and maintaining healthy work environments on project construction sites. Construction Management and Economics, 34 (9). pp. 611-621. ISSN 0144-6193

It is advisable to refer to the publisher's version if you intend to cite from the work. http://dx.doi.org/10.1080/01446193.2016.1195911

For more information about UCLan's research in this area go to http://www.uclan.ac.uk/researchgroups/ and search for <name of research Group>.

For information about Research generally at UCLan please go to http://www.uclan.ac.uk/research/

All outputs in CLoK are protected by Intellectual Property Rights law, including Copyright law. Copyright, IPR and Moral Rights for the works on this site are retained by the individual authors and/or other copyright owners. Terms and conditions for use of this material are defined in the policies page.

\section{CLoK}

Central Lancashire online Knowledge www.clok.uclan.ac.uk

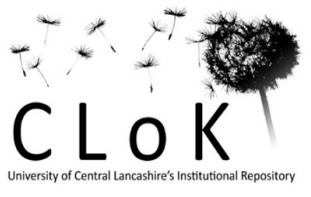


1 Line managers and health promotion on construction sites: Fair deal or another responsibility in an already overloaded role?

\section{Keith Townsend, Ph.D.}

6 Associate Professor, Department of Employment Relations and Human Resources, 7 Griffith University, Australia (corresponding author). Email:

8 k.townsend@griffith.edu.au.

9 Rebecca Loudoun, Ph.D.

10 Senior Lecturer, Department of Employment Relations and Human Resources, Griffith

11 University, Australia. Email: r.loudoun@griffith.edu.au.

12 Katherine E. Markwell, Ph.D.

13 Research Fellow, Department of Employment Relations and Human Resources, 14 Griffith University, Australia.

17 Abstract

19 Research on healthy work environments has grown in importance over the last two 20 decades. Possible explanations for this include the growing recognition and 21 understanding of the determinants of healthy work environments and the associated 22 workers compensation and other organizational costs when they are not managed. It is 23 well accepted that stressful work environments tend to result in negative organizational 24 and individual health indices. Very little is known, however, about the impact of 25 stressful work environments on the dietary habits of workers. Work Safety is often 
researched in construction as the sector tends to have higher injury rates than many other sectors. The focus of this paper is work environments in project based construction work. Our interest is the intersection between an industry in which long hours are worked, wellbeing that is dietary related, and the role of line managers.

\section{Introduction}

Creating an positive food environment at work is important because poor dietary habits forms one of the five main risk factors (along with smoking, insufficient daily activity, excessive alcohol intake and obesity) for many so called 'lifestyle' or 'behavioral' diseases such as Type 2 diabetes and cardiovascular disease (CVD) (Alwan 2011). Together these risk factors form four of the five top contributors to noncommunicable diseases (NCD) worldwide (WHO 2012). Taking a global perspective NCDs are estimated to be the cause of 36 million deaths, or $63 \%$ of the 57 million deaths in 2008 (WHO 2012). At an organizational level, research shows that the health risk profile of a workforce is likely to have a significant impact on total labour costs and also on organizational performance through reduced employee performance, turnover, absenteeism, safety, and morale, and in construction, early exit from the industry (Oude Hengel et al. 2012). Furthermore, employees' poor health is not confined to their own performance, but also impacts negatively, the performance of others with whom they work (Goetzel and Ozminkowski, 2008; Collins et al. 2005).

Like in the general population, an unhealthy lifestyle is commonly seen throughout sections of the construction industry; at least in the geographical area of this research the eastern seaboard of Australia. Research indicates that blue-collar men are at increased risk of premature deaths from a range of NCDs including diabetes, colorectal 
51 cancer, CVD and melanoma (AIHW 2010). Statistics show harmful alcohol 52 consumption, rates of smoking, prevalence of overweight and obesity and so on are 53 considerably higher in construction than in the general male population (Alwan 2011).

54 Since a substantial part of the ageing population in the construction industry has an 55 unhealthy lifestyle, morbidity in this group is likely to rise in the upcoming years 56 (Groeneveld et al. 2008). Absenteeism as a result of CVD and other chronic diseases may also increase at a significant productivity burden to the industry.

59 The work environment in the construction industry is generally considered to be highly 60 demanding, with longer than average working hours compared to many other industries 61 (Lingard et al. 2008; Townsend et al. 2012). Many construction sites operate on a sixday week or even a thirteen-day fortnight basis, and professionals and managers work many hours of unpaid overtime (Townsend et al. 2012). Sites often begin operation (or

64 'pre-start' meetings) at 6am, requiring workers - many of whom do not live close to 65 the worksite and catch public transport owing to parking difficulties - to leave home 66 very early. Tight deadlines and severe financial penalties if targets are not met add to 67 the stresses on site and result in 'cycle' of activity with peaks and troughs in project 68 work and limited fixed or long-term employment (Lingard et al. 2012). All these 69 characteristics are potential workplace stressors that may impact upon employee health 70 and safety. Work Safety is often researched as the sector tends to have higher injury 71 rates than many other sectors (Loudoun, 2010; Safe Work Australia 2012) but as a research topic, construction worker health and wellbeing has received scant attention 73 to date (Hengle 2013). 
75 This paper holds as a starting point, that the role of construction managers is primarily to ensure the safe completion of a project within a reasonable and agreed timeframe. Worker safety is a managers' responsibility, as it is the workers' responsibility. We examine the role of managers in the longer-term aspect of health and safety - the health component. There is a long history of paternalistic management approaches that are somewhat out of vogue, and we are not suggesting a return to such times. We do, however, recognise that in addition to safety, managers and employees already hold a responsibility for the 'health' of the workforce, as outlined in most progressive legislation worldwide.

The following sections consider research on health in construction and the role of line managers in creating a work environment that supports health. We then provide information on the study's context, along with our research methodology. Following this, we develop a thematic analysis of the influence that line managers have over the health and eating habits of the construction workers in our sites. Having reported our findings we conclude with a discussion of their relevance to the debate about the nature of work in construction, drawing insight from a range of related, but rarely considered, literature, such as health promotion, human resource management and education.

\section{Health and Work Environments in Construction}

Explanations for the elevated risk of CVD in construction generally revolve around the nature of the workforce and entrenched work organization practices in the industry. 
risk of disease, injury, and death (Courtenay 2000; Levant et al. 2009). The industry

101 sector is also the third highest paid sector in Australia (ABS 2013). The health benefits

102 generally accrued with higher economic status however, are not present in this 103 population group, with male blue-collar workers having "poorer than average health 104 outcomes, increased mortality rates, disability, and serious chronic disease" (Kolmet, 105 Marino and Plummer 2006).

107 There have been improvements in safety on construction sites in recent years, but much 108 remains to be done about the continuing poor occupational health of the industry's 109 employees. There has been a growing interest in improving the 'health' of work 110 organization in general years with the majority of large employers now offering 111 wellness programs (Mattke et al. 2013). 'Healthy work organization' is an extension 112 of work organization, with the latter referring to the way work processes are structured 113 and managed, such as job design, scheduling, management, organizational 114 characteristics, and policies and procedures (DeJoy et al. 2010). Healthy work 115 organization focuses on how the structure and fabric of the organization function to 116 impact on the health and wellbeing of employees creating healthy or unhealthy work 117 systems (DeJoy, Wilson and Griffin-Blake 2006).

119 Research in this area has grown in importance over the last two decades owing to the 120 growing recognition and understanding of the determinants of these environments and 121 the associated workers compensation and other organizational costs when they are not 122 managed (e.g., Safe Work Australia 2012; Ostroff and Bowen 2000; Story et al. 2008).

123 Research shows that stressful work environments and associated work-life interference 124 have been associated with negative organization outcomes such as higher levels of 
125 sickness absence (Bergstrom et al. 2007), increased turnover, and reduced 126 organizational citizenship behavior, i.e. the performance of tasks over and above the 127 minimum requirements of the job (Bragger et al. 2005). At an individual level, it is 128 inversely related to general wellbeing, psychological strain, psychiatric disorders and 129 substance abuse (Carlson et al. 2011; Boyar et al. 2003; O'Driscoll et al. 2003; Hammer 130 et al. 2004; Siegrist 2008; Van den Berg et al. 2008).

132 Many areas of workplace research although not exclusively focused on healthy work 133 organization, provide understanding and insight into critical workplace systems. For 134 example, progress in the field of human resources/organizational development area 135 have provided insight into characteristics of high-performance work systems (e.g., 136 Zacharatos et al., 2005; Wood and de Menezes, 2011). Similarly healthy work 137 environments and their job and organizational influences form a major focus of Job 138 stress research (e.g., Cartwright, Cooper and Murphy 1995; deJoy et al., 2010; Peterson 139 and Wilson 2002; Sparks et al. 2001) and health promotion research more broadly (e.g.,

140 DeJoy and Wilson 2003; Goetzel and Ozminkowski, 2008).

142 Attempts to create 'healthy workplaces' in construction have mainly targeted individual 143 workers through lifestyle programs such as on-the-spot health assessments and other 144 preventative health services (Gram et al. 2012; Groeneveld et al. 2011). It is also a 145 growing practice in Australia to link sickness absence management to preventative 146 health programs in the workplace, often involving the insurance sector (Snashall 2005). 147 Interventions that focus on the working environment tend to focus on finding a better 148 fit between physical work demands and individual constraints and capabilities 149 (Luijsterburg et al. 2005). 
151 However, limited gains can be made by aiming interventions at the individual rather

152 than the work system, and the nature of project-based work in construction presents

153 considerable barriers to these attempts. For example, symptoms of occupational illness

154 are in general, less immediately apparent and more difficult to detect than injury, hence

155 development of illnesses is likely to take longer than the generally short lifecycle of

156 project work. It is this short life cycle, however, and subcontracting within the industry,

157 that encourages subcultures to develop (Loosemore and Tan 2000), which may result

158 in an embedded culture that inadvertently promotes poor diets and alcohol misuse (Du

159 Plessis et al. 2013). Despite this, very little work has investigated health and wellbeing

160 considerations for construction workers in project based settings (Turner 2013). It is

161 imperative that researchers investigate this group to determine how behavioral risk

162 factors can be improved for a predominantly full-time cohort, in a masculine culture

163 with unique work arrangements.

165 Within all of these related strands of research the active support of a committed senior 166 management is seen as critical for any improvements in the work environment. This

167 view is consistent across management literature, broad work, health and safety 168 literature, general workplace health promotion literature and in construction 169 specifically defined (Cameron and Duff 2007). Management can create opportunities 170 for workers to be engaged in healthy and safety (Maloney, Cameron and Hare, 2007). 171 At present, however there is very little research on the role of line managers in creating 172 healthy environments. This paucity is significant in construction as site managers are 173 usually the only contact workers have with the principal contracting firm (Styhre 2006).

174 The limited work that has been done focuses on quantitative measures of health and 
wellness and perceptions of support from managers, decision-making climate, and quality of supervision and communication (Dingsdag, Biggs and Sheahan 2008; Kines et al. 2010). Researchers note the prevalence of stress-related disorders in construction due to oppressive management, long work hours, lack of stability, lack of psychological support, poor hygiene on sites and primitive welfare facilitates (Snashall 2005). Very little is known about the role line managers' play in creating and sustaining healthy environments in project-based work in construction, particularly from the point of view of managers themselves (Biggs et al. 2013). In broad health promotion research, Haslam (2002) demonstrates the unwillingness of managers to address workplace health and safety (WHS) problems owing to a 'triangle of constraint', whereby sickness absence can lead to reduced productivity, draining the time and energy of managers, who become unwilling or unable to deal with underlying problems. With the causes still in place, absenteeism continues to rise until an unhealthy workplace culture sets in. Other researchers note that responsibility for workplace health interventions, and liability and risk management issues, often place the consideration of developing and implementing health and wellbeing programs in the "too hard" basket (Du Plessis et al. 2013). Whether line managers in construction face these and other barriers in the context of food environments, however, is unknown.

This empirical, qualitative study aims to help us understand the role of line managers in creating and sustaining the dietary habits of workers across six large construction sites of an Australian construction group. The investigation formed part of a larger research project and served as a preliminary study to inform the methodology of the second stage quantitative investigation into dietary habits in project-based construction. In particular, this research sought to understand the nature and reach of any influence 
line managers play, or should play, in food environments on site as determined by them,

201 other managers on site, and workers themselves.

\section{Methodology}

205 The data used in this paper were collected at five different worksites across the same city. Each of the sites were completing projects involving substantial refurbishment or new-build mixed residential, office and retail space; they had the same construction firm overseeing operations. Ethical approval was granted by Griffith University Human Ethics Committee (EHR/01/14/HREC).

211 We used a purposeful sampling strategy at each worksite to ensure a vertical and 212 horizontal representation of the workforce. At each site the research team interviewed 213 the site manager, the health and safety officer, and the foreman - all employees of the 214 principal contractor - resulting in 15 interviews in total. Following this, interviews were 215 also conducted with the supervisors of three sub-contractors at each site. Fifteen focus 216 groups in total across the sites were then conducted with employees from various trades.

217 The focus groups varied so that an adequate sample of trades was involved, however, 218 the number of employees in these focus groups varied between two and four depending 219 on the availability of employees. Qualitative approaches were used for the research 220 because they have the advantage of providing in depth, rich information about a 221 particular topic, which was appropriate for the purpose of this specific research. 222 Interviews were completed until data saturation was reached. 
224 Our analysis began at the start of the interviewing process and concluded after all data 225 were collected. Specifically, the research team met after the interviews at each site

226 identified preliminary themes or categories that were emerging, to assess the relevance 227 of existing codes to new data, and to discuss relationships between codes (Goetz and 228 LeCompte 1981). The process used through data collection and research team 229 discussions formed a version of convergent interviewing; a technique advocated by 230 Dick (1998) and more recently, Jepson and Rodwell (2008). Jepson and Rodwell argue 231 that the process of convergent interviewing improves the internal validity, external and 232 construct validity of qualitative data techniques.

\section{Results}

236 As one of our key interests was the role that line managers play in the health and safety 237 habits of construction workers focussing primarily on dietary risk factors, we 238 determined it would be a most appropriate approach to simply ask every participant in 239 our qualitative data collection the straight forward question - "what influence can line 240 managers play in the eating habits of construction workers?". The general theme given 241 in response was unanimous, and the most common response was "no influence 242 whatsoever". Some people did elaborate, including one site manager who explained: The line managers have zero influence over what the blokes eat ...I don't think I should have any responsibility over what blokes eat on site. We tell them what to do all day, they can have that for themselves.

247 This view was consistent from employees and all managers throughout the six 248 worksites with another manager stating: 

supposed to do. They're grown men for Pete's sake. They've made it this far in life.

254 Site managers also expressed that they were already too busy with their work role to fit in influencing eating, and that it was outside their role.

While there was a consistently held view that the line managers have no influence over the eating habits of construction workers on their site, the evidence we have suggests otherwise. With responses employees and line managers give, questions asked later in 260 the interviews reveal there are in fact a number of ways that line managers' decisions 261 can (and do) influence the eating habits of employees. Our analysis provides us with 262 three broad themes that we address in order: work pressure/time pressure; environment; 263 and leadership behaviors.

\section{Work Pressure/Time Pressure}

267 The first area where it was clear that line manager decisions have an impact on the 268 eating patterns of construction workers while on site relates to the area of work and 269 time pressure. Numerous employees suggest that they are often feeling time and 270 workload pressures due to deadlines, and that has a real influence on their decision271 making on a daily basis. Employees explain that when the time pressures are high, their 272 decision-making does change, for example: 

...if you hadn't already prepared lunch and if they were already pushing you as hard as you can you're going to go the fast food option just to get enough time to get it.

... (when we are) under the pump and having to get the quick option cause you don't have much time to wait for a sandwich to be made at a shop or something like that ...

You don't have time to wait for something healthy to be made in front of you, there isn't the quick healthy option, you don't have pre-made sandwiches

Additionally, the nature of working hours within the industry, combined with employees often working on projects at least an hour of driving time from their house, means that 4-4:30am is a common wake up time for these workers. Numerous employees tell us that 'the body isn't ready for food at 4am' but they do require food and sustenance prior to starting work. As one employee explains: ... most blokes won't want to get up at 4 am to get something healthy. If you go past McDonalds at 5 (am) in the morning you'll see utes (utility vehicles) lined up around the corner. 

breakfast (have) energy drinks and smokes.

302 The time and work pressures that have long been associated with the construction 303 industry clearly have some impact on the eating habits of the workers. These work 304 hours have a long history in construction and are ingrained in the culture of the industry, 305 which makes the ability of line managers to influence these starting times more limited. 306 However while limited, the site managers' influence was not negligible with one 307 choosing to not open the site on Saturdays and others choosing to finish early on Fridays as a direct attempt to change the long hours culture at least at site level.

\section{Environment}

312 Our second clear theme that is drawn from the data is the environment. It was very clear

313 from the interviews that line managers make some decisions that relate to the work 314 environment, and these decisions have an influence over the eating habits of employees 315 on the site. In every site there are activities that are central to the planning that line 316 managers make, for example, the number and positioning of 'eating areas', the number 317 and positioning of water fountains, and the availability of vending machines. These are 318 decisions that have a direct impact on the eating habits of the employees, as our data demonstrates. 
The smaller the site is the easier it is to heat up something from home because it's not far to the meal rooms. So the set up of the site becomes important if you have to walk five minutes to get to it then it changes the way you eat.

Coupled with this comment, the size of the site and where a site manager decides to locate 'smoko rooms', becomes important for employees.

This is a big site, we've got something like 20 floors. And if I'm working too far away from the smoko room, by the time I down tools, get to the room, heat up my meal, sit down an eat it, all my time is gone. It's much quicker and easier to dive out the back gate to the pie shop and get something and have a bit of a breather.

333 Employees tell how the set out of the eating environment is important. They want the rooms to be a comfortable size and well lit. One employee compares quite positively the current worksite to previous ones he has been on: ... (this room is) better. Massive smoko shed - an eatery pretty much!

Interestingly, on this site the site-manager made the point that he felt the eating environment was very important for employees and that he had planned it very carefully to ensure there was a spacious, well lit area for the workers to relax during their breaks. Many employees echo these sentiments and further explain the importance of storage spaces (refrigerators, etc.) and reheating facilities like microwave ovens. In many sites

344 matters of refrigerators and microwave ovens can be dictated in the union-management 345 negotiated enterprise bargaining agreements for the site. Other sites have canteens and 
346 a number of employees suggest that when they have worked on sites with canteens,

347 their overall decision-making about food choices is improved. Hence, the idea of

348 managers influencing eating habits in this manner is not an unnecessary impost, 349 managers are making these decisions already, and these decisions are influencing 350 employee eating habits.

351

352 One line manager was formerly a chef and has taken it upon himself at every site he 353 works to arrange better quality food alternatives for the site staff. As he explains: ... (I) organise a (nearby) cafeteria to have special construction site discount meal deals, salad sandwich and OJ 'bargain'. We commit bulk numbers, for example, 90 blokes, send business their way ... I've done it here with Milano's

Akin to this idea is the notion of having payroll deductions for quality food deliveries.

361 As one employee states: cheap so everyone ate better on that site.

366 All the construction sites in our sample had vending machines. Some vending machines were for drinks only and mostly filled with high sugar cans of popular varieties, while some had food vending machines with packets of chips (crisps) and chocolates. Many employees and line managers suggest that the decisions to have these vending machines 
on site with what would be considered unhealthy options would be just as easily

371 changed to include more healthy eating and drinking alternatives.

One site manager says:

Most people buy drinks from the machine - they're $\$ 1.20$ so pretty cheap ... I suppose in reality I could not have the coke machine here, and that would take away the option, they'd get the shits for a while...

When asked directly if he tries to influence what employees drink on site, one manager says:

I do, probably, yeah I definitely do, probably uh ... I've got some guys who I actually believe they're energy drink addicts, and I do speak to them about it, but once again, 98\% of the time like, I, it's laughter is the reply. ... obviously I can't stop them, but I try to get them to cut down and drink more water, that's part of my role here definitely, just to keep them on their feet all day.

Because the sub-tropical climate does create a hot and humid environment, the importance of hydration is very important on sites, particularly in summer. Employees suggest that the presence of vending machines is not the problem for them - it's what is in the vending machines. Here the tension between individual choices becomes apparent, as one employee states: 

... you've got to pay money to get it, ... if you get something from a vending machine that's not healthy it's your decision you know 'cause you put the money in and press the number, you know so ... I don't think that's affecting poor eating on site, yeah, it's your choice, to eat poorly.

399 Clearly some managers have an influence over the work time eating habits of the workers on site through their planning of the on-site eating environment. Areas identified by employees and managers that had a positive influence on their decisionmaking were the spacious, well lit, and well 'fit-out' designated eating areas; and the 403 opportunity to have good quality food on site either through an eatery or with an arrangement with a local supplier. The positioning of designated eating areas seem to have both a negative and positive impact - those sites with numerous, well positioned areas were seen as more beneficial compared with those sites that had fewer areas resulting in a longer time for the employees to get there in short breaks. Finally, the

408 decisions to have drink machines on site and equally as important, what to include in 409 those drink machines was a clear area of influence over which the line managers had control.

\section{Behavioral Influence}

414 The final theme that developed from our data was the notion of behavioral influence. 415 By behavioral influence we refer to the sorts of actions that line managers take over 416 food consumption for themselves or for the site which leads to what would commonly 417 be called 'custom and practice' or a 'workplace culture'. Again, despite employees and 418 managers alike agreeing that the managers have 'no influence' over worker eating 
habits, our evidence suggests to the contrary. As one employee refers to a site he has worked on where the manager takes a great deal of care over his own diet: Although in some cases, I suppose at the Nundah job ... a lot make their food on site I think they see (the site manager) making his own lunch.

This influence of line managers is further demonstrated when workers reminisce on their early years of employment:

My supervisor brings his lunch every day. So I guess you just do what everyone in the crew does. You don't want to be the guy that takes off to the shops, you get

And:

I remember when I was on the tools I was always keen to see what someone was bringing in, what leftovers. If someone bought something from a shop you'd comment on it but there's always a joke when someone goes to the shop. It was never a welcome choice.

.... if a bloke wants to go off site and get something, and the supervisors bring their sangas (sandwiches), then they'll get the shits with the blokes running off site or going to heat things up in the kitchen... 
443 Again, it is clear that employees are influenced by their line managers, but the influence

444 is on first consideration somewhat hidden. Commonplace on constructions sites is the 445 'site bar-be-que' (BBQ). Again, it is clear to everyone that this is a choice that is made 446 by line managers to have the BBQ, what they serve at the $\mathrm{BBQ}$, and for individual 447 employees to eat at the BBQ. Some of our line managers' state:

We do put on a BBQ with a can of coke. We did start with juice but cheaper and easier to get coke for 50c can.

We run site BBQs so can influence that-steaks, sausages, onions, eggs. If it was healthy they'd eat it but would complain. It's a fine line. It takes time but if we can we should try to improve eating habits. It would improve morale and get

And an employee comments: BBQs because I feel crap all day but everyone else rushes down there.

Discussion

464 Overall, our findings indicate considerable disparity between the views of managers 465 and workers about the perceived influence of managers in creating and influencing the 466 food environment and food habits and choices on site and the reality of their 467 considerable influence. The findings reflect an apparent cognitive dissonance 
468 (Festinger 1962) between what is actually occurring (multiple influences) and what is 469 perceived to be occurring (i.e. no influence). Views regarding personal responsibility 470 appeared to shape perceptions of influence, creating a 'silo' effect where actual

471 influences are noticed but not taken into the silo.

473 It is difficult to explain this disparity. Certainly, beliefs that an individual's personal 474 responsibility and choice are primarily driving food intake are prevalent and persistent. 475 Personal responsibility is a key argument in the obesity epidemic, in particular by the 476 food industry with regards to food choices (Brownell et al. 2010). Further, 477 “...judgments about obesity are linked to values of individualism, self-determination, 478 political conservatism, and secular morality" (p382). Australian society has an 479 individualistic focus that may be underpinning the observed silo.

Another body of literature that may provide some insight into these issues is the hidden curriculum literature found within education. This literature argues that there is a 483 'hidden curriculum', a distinction between the curriculum that is officially stated by the 484 educational system, "and what teachers and learners actually do and experience on the ground, a kind of de facto curriculum" (Sambell and McDowell 1998). Snyder first raised this notion in the 1970s, suggesting that at the Massachusetts Institute of 487 Technology, the formal curriculum places an emphasis on higher order educational 488 goals like independent thinking, while the assessment items suggested that the hidden 489 curriculum involved memorising facts to achieve success. Within the construction 490 industry there will be a range of trades and labourers working together on projects, each 491 with their own knowledge, skills and attitudes that are specific to their trades. 492 Educational experts claim that regardless of the formal training through educational 
493 institutions, it is the hidden curriculum in workplaces where learning actually occurs

494 (Galbraith, Clyman and Melnick 2011).

496 The results of this study suggest that one aspect of the hidden curriculum that 497 construction workers learn is around dietary behaviors. It is our view that a central part 498 of this hidden curriculum can be conceptualised as the 'hidden influence' line managers 499 have over the eating habits of employees, much akin to the hidden curriculum. Line managers of all levels have a direct influence over employees at the workplace -

501 direction of work, timing of work, interpretation of organizational policies and so on. 502 However, line managers also have an influence over employee actions that is not so 503 explicit.

505 Within the mainstream management literature in recent decades there is consistent 506 agreement that line managers are crucial to organizational performance (Jacoby 2004). 507 The line managers in this research project are employed by the primary contractor to 508 manage a building site and typically have a small amount of direct employees (usually, 509 three or four), but a large number of sub-contractors reporting to them (there can be up 510 to 200 or more on site).

512 Research in the area of people management within construction often depicts a difficult 513 working environment with long working hours (Townsend et al. 2011; Lingard et al. 514 2008) and high rates of health and safety incidents (Loudoun 2010) among two 515 commonly cited areas of concern. Management styles undoubtedly vary between firms 516 and across countries, making generalisation difficult; nevertheless, the sector is 517 perceived to approach human resource management and union-management relations 
rather poorly (ILO 2001). It is the two aforementioned areas of research (working hours

519 and safety) that would appear to have a strong relationship with our primary area of

520 concern - consumption habits of construction workers.

521

522 It appears that in order to improve food choices in workers, due to the observed 523 relationships, a 'comprehensive approach' is needed. This approach, advocated for by 524 Noblet and LaMontagne (2006) for implementing job stress health promotion 525 programs, would incorporate both individual and organizational interventions. For 526 instance, work support has previously been found to influence both mental health and 527 good health (Love, Edwards and Irani 2010). Whilst immediate supervisors and managers do have some reported impacts on behavior and environment, time pressures would be expected to be less modifiable at a site level.

531 In a Canadian auto setting, general and human resource managers' motivations for 532 worksite health promotion were improving indirect health costs (Downey and Sharp 533 2007). General Managers were also motivated by moral obligation. In this study, there 534 was an undercurrent in supervisor interviews of a moral obligation for safety, but this 535 perceived obligation did not appear to overlap into healthy behaviors. This also reflects 536 the disconnect between the priority of occupational health and safety in most Australian 537 industrial settings. Economic benefits can be definitely accrued and demonstrated by 538 safety interventions (e.g., Tompa et al. 2008), whereas health promotion interventions 539 have tangible costs but less tangible outcome savings (Downey and Sharp 2007). 540 Supervisor energy is focused on safety and productivity measurable outcomes. 541 However, adopting a 'human capital framework' that focuses on both health and safety 542 (Goetzel and Ozminkowski, 2008) could lead to productivity gains. 


\section{Conclusion}

546 Personal liberties and choice is an important element of living and working in a liberal-

547 democratic nation, and we do not wish to imply that this research is designed, or is

548 suggesting that, personal liberties and choices should be impinged upon in the

549 workplace. What we have investigated here is the notion of decisions that are already

550 being made in workplaces, and the way line managers are already having an influence

551 over employee dietary habits. We have drawn on a theory from the education realm -

552 the 'hidden curriculum'. The hidden curriculum refers to the notion that there is a

553 formal curriculum that is espoused, but surrounding this is a 'hidden' curriculum that

554 students soak up as they progress through their educational experience.

556 In this article, we have also drawn on the broad human resource management and

557 employment relations literature on line managers that clearly demonstrates that the

558 many levels of line managers in workplaces play a central role in influencing

559 performance at the workplace. These two elements combined to provide us with the

560 scope to understand what the perceptions on construction sites were about the role of

561 line managers in influencing employee dietary habits. It was clear that all participants

562 in our study viewed line managers to have 'no influence', but the data collected

563 indicated something quite to the contrary. Hence, we deemed the question of whether

564 line managers should be involved in promoting healthy food choices and habits onsite

565 to be a redundant question. Our findings show line managers are already having a

566 'hidden influence' over the consumption of workers at their site even though it is largely

567 unintended. This influence does not impinge on personal choice, however, line 
568 managers already make decisions that could be changed and with these changes, a 569 positive impact on employee consumption is likely to follow.

\section{$570 \quad$ References}

571 ABS (Australian Bureau of Statistics). (2013). “6306.0 Employee earnings and hours, 572 Australia, May 2012.” ABS, Canberra, Australia.

573 Alwan, A. (2011). Global status report on noncommunicable diseases 2010. WHO $574 \quad$ (World Health Organization).

575 AIHW (Australian Institute of Health and Welfare). (2010). "Australia's health 2010 576 in brief." Australian Institute of Health and Welfare, Canberra, Australia.

577 Bergström, G., Bodin, L., Bertilsson, H., and Jensen, I. B. (2007). "Risk factors for new 578 episodes of sick leave due to neck or back pain in a working population. A prospective study with an 18-month and a three-year follow-up." J. Осcup. Environ. Med., 64(4), 279-287.

581 Biggs, S. E., Banks, T. D., Davey, J. D., and Freeman, J. E. (2013). “Safety leaders' perceptions of safety culture in a large Australasian construction organisation." Saf. Sci., 52, 3-12.

Bragger, J. D., Rodriguez-Srednicki, O., Kutcher, E. J., Indovino, L., and Rosner, E. (2005). "Work-family conflict, work-family culture, and organizational citizenship behavior among teachers.” J. of Bus. Psychol., 20(2), 303-324.

587 Brownell, K. D., Kersh, R., Ludwig, D. S., Post, R. C., Puhl, R. M., Schwartz, M. B., 588 and Willett, W. C. (2010). "Personal responsibility and obesity: a constructive 589 approach to a controversial issue." Health Affairs, 29(3), 10.1377/hlthaff.2009.0739, 379-387. 
591 Cameron, I., and Duff, R. (2007). "Use of performance measurement and goal setting to improve construction managers' focus on health and safety." Constr. Manage. Econ., 25(8), 869-881.

Collins, J. J., Baase, C. M., Sharda, C. E., Ozminkowski, R. J., Nicholson, S., Billotti, G. M., Turpin, R. S., Olson, M., and Berger, M. L. (2005). "The assessment of chronic health conditions on work performance, absence, and total economic impact for employers." J. Occup. Environ. Med., 47(6), 547-557.

Carlson, D. S., Grzywacz, J. G., Ferguson, M., Hunter, E. M., Clinch, C. R., and Arcury, work-family interface: An analysis across time.” J. Appl. Psychol., 96(5), 1045.

Cartwright, S., Cooper, C. and Murphy, L. (1995) "Diagnosing a healthy organization: A proactive approach to stress in the workplace." in Murphy, Lawrence R., Joseph interventions. American Psychological Association, 1995. (pp. 217-233). Washington, DC, US: American Psychological Association, xiii, 439 pp.

Courtenay, W. H. (2000). "Engendering health: a social constructionist examination of 608 men's health beliefs and behaviours." Psychol. Men Mascul., 1(1), 4-15.

DeJoy, D. M., Wilson, M. G., and Griffin-Blake, C. S. (2006). "Healthy work 609 organization.” In W. Karwowski (Ed.) International Encyclopedia of Ergonomics and Human Factors, 2nd Ed., Taylor and Francis, London, U.K.

611 DeJoy, D. M., Wilson, M. G., Vandenberg, R. J., McGrath-Higgins, A. L., and GriffinBlake, C. S. (2010). "Assessing the impact of healthy work organization

614 Dick, B. (1998). "Convergent interviewing: a technique for qualitative data collection." $615<$ http://www.aral.com.au/resources/iview.html> (Mar. 18, 2013). 
616 Dingsdag, D. P., Biggs, H. C., and Sheahan, V. L. (2008). "Understanding and defining 617 OH\&S competency for construction site positions: Worker perceptions." Saf. 618 Sci., 46(4), 619-633.

619 Downey, A. M., and Sharp, D. J. (2007). "Why do managers allocate resources to 620 workplace health promotion programmes in countries with national health 621 coverage?" Health Promo. Int., 22(2), 102-111.

622 Du Plessis, K., Cronin, D., Corney, T., and Green, E., (2013). “Australian blue-collar 623 men's health and wellbeing: Contextual issues for workplace health promotion 624 interventions." Health Promo. Prac., 14(5), 715-720.

625 Festinger, L. (1962). A theory of cognitive dissonance, Vol. 2. Stanford University 626 Press, Redwood City, CA.

627 Galbriath, R., Clyman, S., and Melnick, D., (2011). "Conceptual perspectives: 628 Emerging changes in the assessment paradigm.” In J. Hafler (Ed.) Extraordinary 629 learning in the workplace. Innovation and Change in Professional Education $630 \quad$ Series, Springer, New York.

631 Goetz, J., and M. LeCompte (1981). "Ethnographic research and the problem of data 632 reduction", Anthro. Educ. Quart., 12(1), 51-70.

633 Goetzel, R. Z., \& Ozminkowski, R. J. (2008). "The health and cost benefits of work 634 site health-promotion programs.” Annu. Rev. Public Health, 29, 303-323.

635 Gram, B., Holtermann, A., Sogaard, K., Sjogaard, G. (2012). "Effect of individualized 636 worksite exercise training on aerobic capacity and muscle strength among 637 construction workers - a randomized controlled intervention study." Sc. J. Work $638 \quad$ Environ. Health, 38(5), 467-475.

639 Groeneveld, I. F., Proper, K. I., Van Der Beek, A. J., Hildebrandt, V. H., and Van 640 Mechelen, W. (2011). "Short and long term effects of a lifestyle intervention for 
construction workers at risk for cardiovascular disease: a randomized controlled trial.” BMC Public Health, 11 (Oct 31), 836.

643 Groeneveld, I. F., Proper, K. I., Van Der Beek, A. J., Van Duivenbooden, C., and Van 644 Mechelen, W. (2008). "Design of a RCT evaluating the (cost-) effectiveness of a 645 lifestyle intervention for male construction workers at risk for cardiovascular 646 disease: the health under construction study." BMC Public Health, 8(1), 1.

647 Hammer, T. H., Saksvik, P. Ø., Nytrø, K., Torvatn, H., \& Bayazit, M. (2004). 648 "Expanding the psychosocial work environment: workplace norms and work649 family conflict as correlates of stress and health.” Journal of Occupational Health $650 \quad$ Psychology, 9(1), 83.

651 Haslam, R. A. (2002). "Targeting ergonomics interventions-learning from health 652 promotion." Appl. Ergonomics, 33(3), 241-249.

653 Hengel, K. M. O., Blatter, B. M., van der Molen, H. F., Bongers, P. M., \& van der Beek, 654 A. J. (2013). "The effectiveness of a construction worksite prevention program on work ability, health, and sick leave: results from a cluster randomized controlled trial." Scandinavian journal of work, environment \& health,39(5), 456-67.

ILO (International Labour Organization). (2001). "The construction industry in the twenty-first century: its image, employment prospects and skill requirements", International Labour Organization, Geneva, Switzerland.

660 Jepsen D \& Rodwell J (2008) Convergent interviewing: a qualitative diagnostic 661 technique for researchers, Management Research News, 31 (9), $650-658$

662 Kines, P., Andersen, L. P., Spangenberg, S., Mikkelsen, K. L., Dyreborg, J., and Zohar, 663 D. (2010). "Improving construction site safety through leader-based verbal safety 664 communication.” J. Saf. Res., 41(5), 399-406. 
665 Kolmet, M., Marino, R., and Plummer, D. (2006). “Anglo-Australian male blue-collar 666 workers discuss gender and health issues." Int. J. Men's Health, 5(1), 81-91.

667 Levant, R. F., Wimer, D. J., Williams, C. M., Smalley, K. B., and Noronha, D. (2009). 668 "The relationship between masculinity variables, health risk behaviors and attitudes 669 toward seeking psychological help.” Int. J. of Men's Health, 8(1), 3-21.

670 Lingard, H., Townsend, K., Bradley, L., and Brown, K. (2008). “Alternative Work 671 Schedule Interventions in the Australian Construction Industry: a comparative case 672 study analysis." Constr. Manage. Econ., 26(10), 1101-1112.

673 Lingard, H., Francis, V., \& Turner, M. (2012). "Work-life strategies in the Australian 674 construction industry: Implementation issues in a dynamic project-based work 675 environment." International Journal of Project Management, 30(3), 282-295.

Luijsterburg, P.A., Bongers, P. M., de Vroome, E. M. (2005). “A new bricklayers' method for use in the construction industry." Sc. J. Work Environ. Health, 31(5), $394-400$.

Loosemore, M., and Tan, C. (2000). "Occupational stereotypes in the construction 680 industry." Constr. Manage. Econ., 18, 559-566.

681

Loudoun, R., (2010). “Injuries sustained by young males in construction day and night 682 work.” Constr. Manage. Econ., 28(10), 1313-1320.

Love, P. E. D., Edwards, D. J. and Irani, Z. (2010). "Work stress, Support, and Mental 684 Health in Construction.” J. Constr. Eng. Manage., 136, 650-658.

685 Maloney, W. F., Cameron, I. and Hare, B. (2007). "Tradesmen Involvement in Health 686 and Safety." J. Constr. Eng. Manage., 133, 297-305. and Shier, V. (2013). “Workplace wellness programs study.” Rand Corporation, Santa Monica, CA. 
Noblet, A., and LaMontagne, A. D. (2006). "The role of workplace health promotion in addressing job stress." Health Promo. Int., 21(4), 346-353.

Ostroff, C., \& Bowen, D. E. (2000). "Moving HR to a higher level: HR practices and organizational effectiveness" in Klein, Katherine J., Kozlowski, Steve W. J. (Eds.) Multilevel theory, research, and methods in organizations: Foundations, extensions, and new directions. (pp. 211-266). San Francisco, CA, US: JosseyBass, xxix, 605 pp.

Oude Hengel, K. M., Blatter, B.M., Geuskens, G.A., Koppes, L. L., and Bongers, P. M. (2012). "Factors associated with the ability and willingness to continue working until the age of 65 in construction workers." Int. Arch. Occup. Environ. Health, 85(7), 783-790.

Peterson, M., and Wilson, J. F. (2002). “The culture-work-health model and work stress." American Journal of Health Behavior, 26(1), 16-24.

Sambell, K., and McDowell, L. (1998). "The construction of hidden curriculum: messages and meanings in the assessment of student learning." Assess. Eval.

Safe Work Australia (2012). “Compendium of workers' compensation statistics Australia 2009-10." Safe Work Australia, Canberra, Australia.

Siegrist, J. (2008). "Chronic psychosocial stress at work and risk of depression: Evidence from prospective studies. European archives of psychiatry and clinical

711 Snashall, D. (2005). "Occupational health in the construction industry." Sc. J. Work 712 Environ. Health, 31, (2), 5-10.

713 Snyder, B. (1971). The hidden curriculum, Knopf, New York. 
714 Sparks, K., Faragher, B., and Cooper, C. L. (2001). "Well-being and occupational 715 health in the 21st century workplace.” Journal of Occupational and Organizational $716 \quad$ Psychology, 74(4), 489-509.

717 Story, M., Kaphingst, K.M., Robinson-O’Brien, R., and Glanz, K. (2008). “Creating 718 healthy food and eating environments: policy and environmental 719 approaches.” Annu. Rev. Public Health, 29, 253-272.

720 Styhre, A. (2006). "The bureaucratization of the project manager function: the case of the construction industry." Int. J. Proj. Manage., 24(3), 271-276.

722 Tompa, E., De Oliveira, C., Dolinschi, R., and Irvin, E. (2008). “A systematic review of disability management interventions with economic evaluations." J. Occup. Rehab., 18(1), 16-26.

Townsend, K., Lingard, H., Bradley, L., and Brown, K., (2012). “Complicated working time arrangements: a construction industry case study." J. Constr. Eng. Manage., 138(3), 443-448.

Townsend, K., Lingard, H., Bradley, L., and Brown, K. (2011). "Working time 730 alterations in the Australian construction industry." Personnel Review, 40(1), 7086.

Turner, M. (2013). "The development of a work-life fit model: a demands and resources approach.” Int. J. Managing Proj. Bus., 6(4), 792-801.

Van Den Berg, T. I., Alavinia, S. M., Bredt, F. J., Lindeboom, D., Elders, L. A., and 734 Burdorf, A. (2008). "The influence of psychosocial factors at work and life style on health and work ability among professional workers." Int. Arch. Occup. Environ. Health, 81(8), 1029-1036. 
737 WHO (World Health Organization). (2012). "World health statistics 2012.” WHO,

738 Geneva, Switzerland. <apps.who.int/iris/bitstream/10665/44844/1/

739 9789241564441_eng.pdf> (Oct. 19, 2014).

740 Wood, S., and de Menezes, L. M. (2011). "High involvement management, high-

741 performance work systems and well-being." The International Journal of Human

$742 \quad$ Resource Management, 22(07), 1586-1610.

743 Zacharatos, A., Barling, J., and Iverson, R. D. (2005). "High-performance work

$744 \quad$ systems and occupational safety." Journal of Applied Psychology, 90(1), 77.

745

746 